SHS Web of Conferences 2, 00028 (2012)

DOI: $10.1051 /$ shsconf $/ 20120200028$

(C) Owned by the authors, published by EDP Sciences, 2012

\title{
Main tasks of social worker in reducing poverty for families with children and social inclusion policy in Latvia
}

\author{
I. Skrodele-Dubrovska
}

Rīga Stradinsš University, Latvia

\begin{abstract}
Social exclusion is an inability of an individual or a group of persons to integrate into society due to poverty, insufficient education, unemployment, discrimination or other causes in Latvia. Welfare of families is influenced not only by the employment of its members, but also by the amount of their salary. Limited amount of family's financial resources make a person to refuse himself a lot of things or restrict expenses to minimum thus increasing the risk of exclusion of the household. When finding a solution of social problems faced by families with children it is essential to involve a social worker. Well-being of children must be in focus of social work practice, in addition taking the special care for their safety and welfare.
\end{abstract}

Key words: social exclusion, social inclusion, social work, at-risk-of-poverty rate, poverty

Social inclusion is a process which ensures that those at risk of poverty and social exclusion gain the opportunities and resources necessary to participate fully in economic, social and cultural life and to enjoy a standard of living and well-being that is considered normal in the society in which they live, as well as greater participation opportunities in decision making and access to their fundamental rights. Main population groups that are mostly subjected to risk of poverty and social exclusion in Latvia are large families with three and more children and single parent (mainly women) families. Social worker is a provider of assistance for the most vulnerable population groups in the society including families with children but social worker can not fully address social problems alone. The vulnerable groups themselves should be motivated to participate in changes and cooperation of people themselves is one of the preconditions for public development.

\section{Results}

One of the population groups mostly subjected to the risk of poverty and social exclusion are families with children. In Latvian public space the concepts of social exclusion and social inclusion entered in relation to preparation of Latvia to join the European Union (EU), when government of Latvia undertook to comply with EU social policy guidelines and prepared the first National Action Plan for Reduction of Poverty and Social Exclusion (2004).

In the European Union member states 'poverty' is mostly related to insufficient income and other resources, for example, social and cultural which are so inadequate as to preclude them from having a living standard considered acceptable in the society in which they live. While the term 'social exclusion' is a broader term than 'poverty'. Social exclusion is understood as a process whereby an individual because of poverty, insufficient education, discrimination or other reasons is fully or partly excluded from society and cannot participate in its economic, social and cultural life. Socially excluded people have difficulties to partly or fully realize their potential to obtain sufficient income and receive different goods and services essential for living, and protect their rights.

This is an Open Access article distributed under the terms of the Creative Commons Attribution License 2.0, which permits unrestricted use, distribution, and reproduction in any medium, provided the original work is properly cited. 


\section{SHS Web of Conferences}

Poverty in its essence is inconsistent indicator since even minimal fluctuations may shift the household from the poor category to another one where the household does not count as poor. Usually the poverty level is defined as a necessary amount of money for one person to purchase a certain basket of goods.

Poverty combines various social problems thus making a set of social problems; it does not exist as one specific social problem separated from other. The higher risk to become socially excluded is especially for poor people as poverty is the main cause of social exclusion (Room, 1999).

In Latvia there is not defined an official poverty threshold or amount of resources per one adult that is adopted as a critical minimum as it is in other European Union member states. A needy person in Latvia is an individual whose income during last three months per one family member does not exceed 90 Ls (158 USD) per person per month and this person:

- does not own monetary accumulations in credit institutions;

- does not hold securities (except of privatization and compensation certificates);

- does not have debt obligations;

- does not own a property that could be used for gaining of income;

- has not entered into maintenance contracts;

- is not on full support of the state or local government; and

- has not issued a loan.

The compliance of the income and material situation of a person with the needy level is assessed and a decision regarding the compliance of a person with the status of a person in need is taken by the social service office of that local government or the local government council in the territory of which the person has registered its place of residence.

In Latvia poverty is measured also by means of methodology of the European Union Statistical Office (EUROSTAT) since, as stated above, in Latvia there has not been defined official at-risk-ofpoverty threshold or poverty line. In order to assess and monitor situation in social inclusion field there are applied the so-called monetary poverty indicators calculated by the Latvian Central Statistical Bureau (hereinafter - CSB).

At-risk-of-poverty threshold in all European Union member states is accepted as $60 \%$ from the national median income per equivalent. It is calculated by dividing an amount of household income by amount of equivalent consumers residing in households. In calculation of equivalent income the modified equivalence scale by Economic Cooperation and Development is used $(1.0 ; 0.5 ; 0.3)$ - where the first adult is equalized to 1.0, each following household member aged 14 and above -0.5 , but each child aged under 14-0.3.

According to CSB data, at-risk-poverty threshold for single person household in 2010 was 149 lats (338 USD) per month which compared to 2009 decreased for 11 lats (39 USD) per month. However, for household with two adults and two children aged under 14 it amounted to 336 lats (712 USD) which compared to 2009 decreased for 24 lats (83 USD) per month. A proportion of population under the relative poverty line in 2010, i.e. people who received less than 149 lats (338 USD) per month were 19 percents. Also in 2010 the at-risk-of-poverty rate reduced similarly as in 2009 due to decrease of household income generally. It means that slightly below 400000 or one fifth of the Latvian population is subjected to the at-risk-of risk of poverty. Average at-risk-of-poverty rate in the European Union member states (EU 27) is 17 percents which is 9 percentage points less than in Latvia.

As shown in Figure 1 families are subjected to the highest at-risk-of poverty rates - single parent families (with at least one dependent child) and large families ( 2 adults with 3 and more dependent children). Regarding these two kinds of households in 2009 and 2010 there is a tendency for single parent families to be subjected to greater risks of poverty, however, differences are not highly relevant. While situation of large families has improved during 2009 and 2010 and their at-risk-of-poverty rate has decreased for 8 percentage points and reached 37 percentages in 2010. This tendency may be 
Int. Conf. SOCIETY. HEALTH. WELFARE; Congr. of Rehabilitation Doctors of Latvia

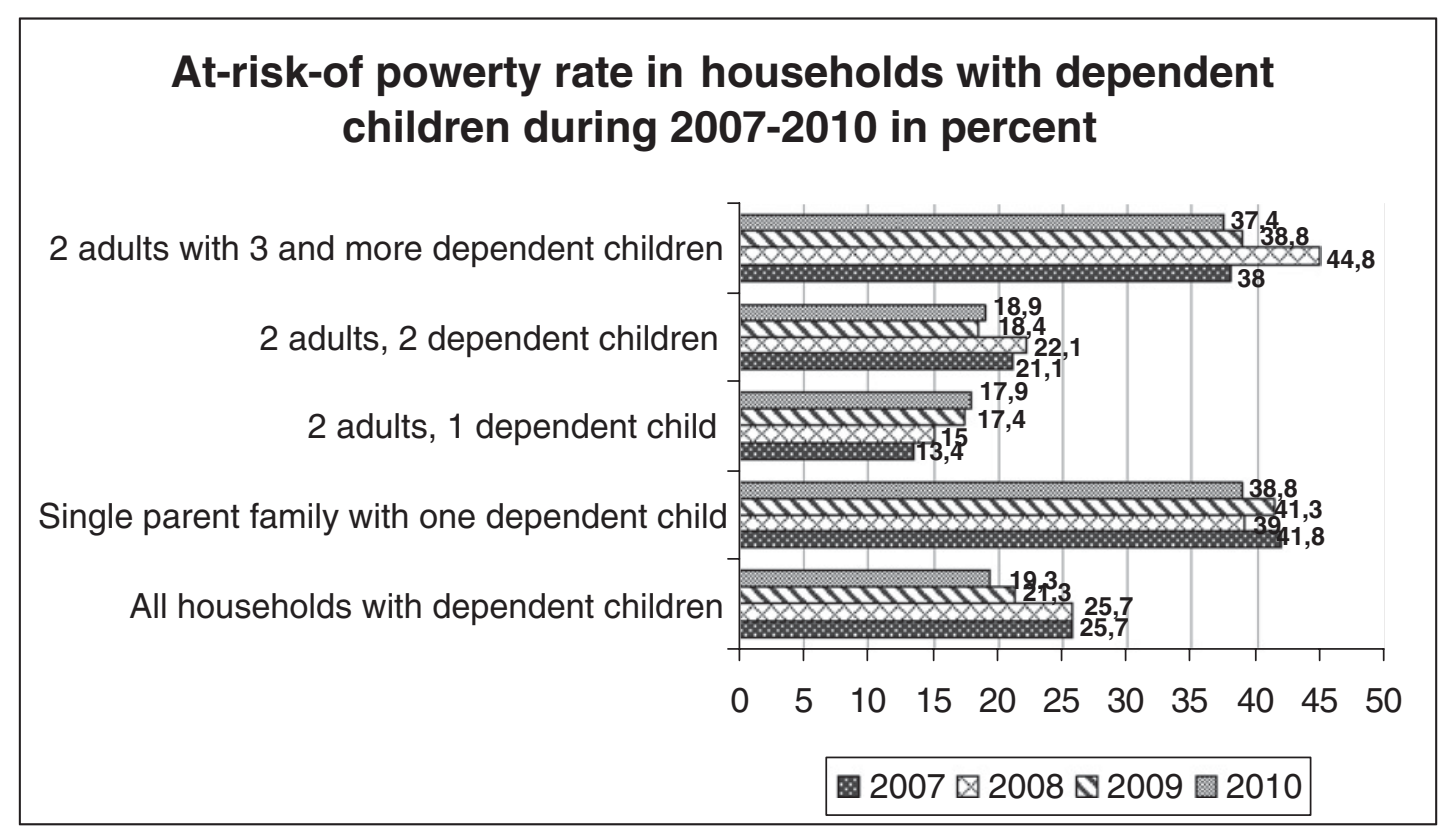

Figure 1. At-risk-of-poverty rate in households with dependent children during 2007-2010 in percent.

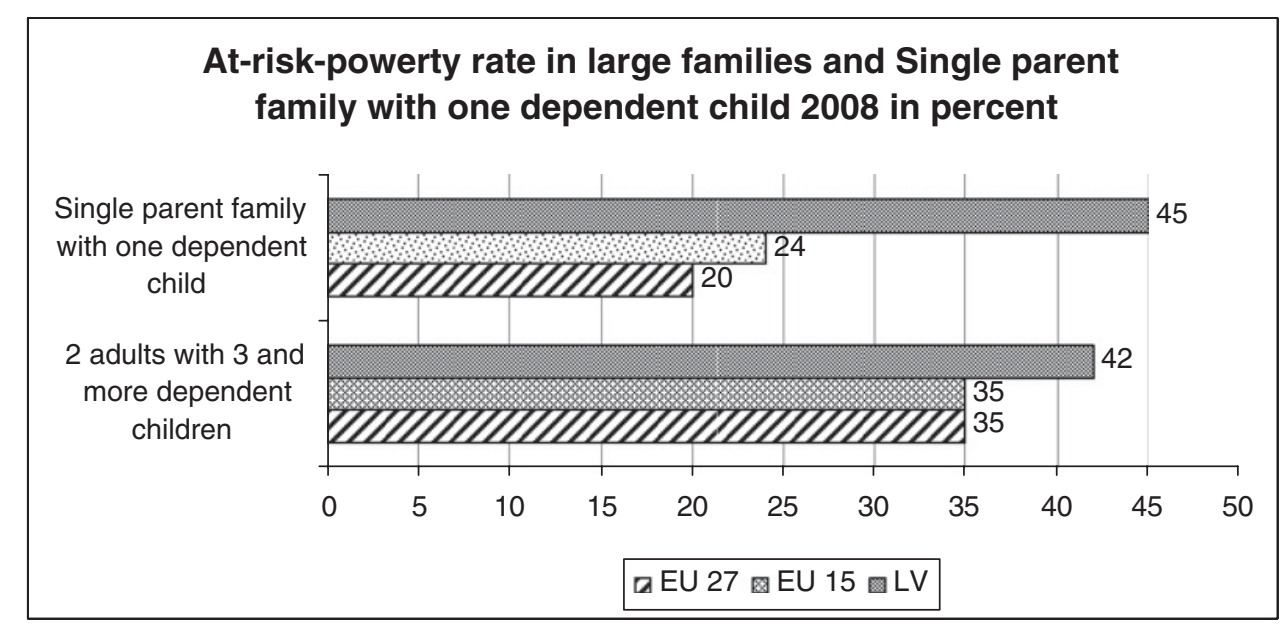

Figure 2. At-risk-of-poverty rate in large families and single parent family with at least one dependent child during 2006-2010.

explained by legislation enforced during crisis when relevant support was targeted to families with children recognized as needy.

Comparing situation of Latvia with all Europen Union member states (EU 27) and old European Union member states (EU 15) with regard to single parent families and large families in Figure 2, we see that in Latvia at-risk-of-poverty rate for large families ( 2 adults with 3 and more dependent children) in 2008 was by 25 percentage points higher comparing to average of all European Union member states (EU 27). While at-risk-of-poverty rate for single parent families compared to all European Union 


\section{SHS Web of Conferences}

member states (EU 27) and old European Union member states (EU 15) was by 7 percentage points higher. However, in general situation regarding large and single parent families in Latvia is disturbing.

Under current socio-economic situation families with children often cannot handle themselves with many problems that arise as a result of rapid economic changes emerged already in the end of 2008. Social and economic instability, uncertainty for the future, relevant changes in values, new opportunities and challenges - this resulted in reduced abilities of families to adapt to new circumstances that expresses in distribution of tendencies unfavourable for society. Demographic crisis, poverty intensification, spread of alcoholism and drugs, increase in proportion of divorces and children born in not registered marriages and out of marriages, increase in number of children left without parental care and placed in child care institutions, etc. - these are consequences of insufficient support and lack of purposefulness in addressing family problems hoping that these problems will solve in their own or families on their own will deal with it. The real situation shows that reliance solely on family is not justified. Nowadays family problems are multihold and there is no evidence that social problems in families will reduce.

In Pranka and Millere analysis on situation in Latvia in child rights protection field with regard to children outside familial care and children under risk to loose their familial care it is concluded that children (0-18 years) in social risk families are about 3 percents of total number of children in Latvia. The main risks faced by these children include insufficient satisfaction of basic needs, physical, emotional as well as sexual violence and children left unattended. These risks are associated with parents' alcoholism, lack of financial resources, lack of skills in upbringing of a child, as well as bad experience of parents in developing family relations thus continuing the reproduction of negative family model. In the beginning of 2008, 2.2 percentage of total number of children in the state were placed in out of familial care. The majority of out of familial care are placed in guardian families (67.7 percentage from all children subjected to out of familial care). The second major care institutions are child care institutions where stayed 26.6 percentage children from all out of familial care children in January, 2008. Foster families as a kind of out of familial care in Latvian practice is still used comparatively rare. In January, 2008 there were placed 5.6 percentage children from total number of children of out of familial care though there is a tendency to increase in the number of foster families.

Each family has its own functions in order to ensure favourable living for family members, to provide care and health for him/herself and children, ensure children a good upbringing, spiritual and emotional health, develop internal and external communication of family. However, each family has its own living situations where risks that threatens family to be socially excluded can arise. This is the way how socially excluded families get into many social problems - unemployment, inability to pay for public utilities and credits, addiction problems, violent behavior towards children and family members, health problems, poor living conditions, lack of resources for everyday needs, etc.

According to Bronfenbrenner, a child always develops in familial relations - ecological model shows how important is the dynamic interaction between the child and environment where the child lives. Ecological perspective emphasizes that the situation of a child shall be researched in full, multidimensional context. By implementing this ecological perspective, helping a child, intervention in assistance process shall be assessed according to various systems that impact welfare of a child and family (Bronfenbrenner, 1979).

Well-being of a family is influenced not only by employment of family members, but also by remuneration received by each able-bodied family member. Limited family material resources make person to refuse from many things or to limit expenditures for consumption up to the maximum thereby increasing exclusion risk for these households. Children from poor and needy families have limited opportunities to go to cinema, theatre, concerts, museums, exhibitions, sport and leisure services, to buy books and other periodicals, use sport and leisure services, purchase audio and video, photo and data processing equipments and accessories, table games, toys, hobby related goods, accessories for sport, fashioned clothes, develop own abilities, to invite other children, to visit other children etc. If a child has no opportunity to go to events and participate in discussion relevant for child and youth, wherewith he 


\section{Int. Conf. SOCIETY. HEALTH. WELFARE; Congr. of Rehabilitation Doctors of Latvia}

or she is being excluded from activities of equals in age. Social contacts of poor children are restricted and these are realized only in environment of equals (Gosh, 2005).

Poverty is a serious obstacle to development of a child. Often poor families cannot pay for accessories needed for children for school, for footwear etc. Therefore children do not attend school and thereby social and intellectual development of a child is being hindered. Not obtaining education, professional qualification and not competing in labour market these young people like their parents become unemployed (Reinholde, Vanaga, 2002).

Living in constant poverty the value orientation of society which lives in need for a long-term substantially changes. Poverty promotes a spread of anti-social behaviour - crime, alcoholism, violence. Disappointment and disbelief in the future prevails in environment of poor people. Poor families are forced to compete basing upon their scarce resources available to them as a result tension among various social groups, for example, retired people and families with children increases.

For the last twenty years there have been made several researches that have provided a clear connection between social inequality or social exclusion, on the one hand, and health condition of specific public stratum, on the other hand. Social, economic and material problems influence health mainly indirectly through such psychosocial filters as tensions or stress, insecurity and various preoccupations (Wilkinson, 1996).

Also environmental insecurity is a relevant aspect in development of child's security sense (Cummings et al., 2000). Child well-being is a long-term problem and it requires preparation of various policies and legal acts, as well as practical, professional action from various specialists.

Social work develops in specific society and in social policy defined by the state and local government. Unfortunately, social work development in Latvia is not as rapid as social problems. One of population groups for whom it is very important to receive social worker services are especially families with children. Child well-being shall be in focus of social work practice, in addition more attention paying to child security and well-being.

Social work undergoes constant development worldwide and it is always targeted at human - its complex and various needs and opportunities to use necessary resources for its realization. In social work context assessment of person as a physical, mental, spiritual and social being that finds itself in constant interaction with processes in society is an integral basic principle.

Social work in municipality is provided by social workers in close cooperation with other social work specialists. Social work specialist in Latvian legislation is defined as a person who has obtained education specified in Law on Social Services and Social Assistance and performs professional duties of social worker, social carer, social rehabilitator or social assistance organizer. An aim of social work is to improve human's as person's, family's, group's, community member's adaptation in real environment, so that person can find the best possible way for growth and development, and survival. Besides, it is necessary to search, develop and change environmental factors to create optimal circumstances for individual to develop its abilities and interests. Social work always has been based on humanistic approach - implementation of social justice idea in society, as well as provision of human dignified living conditions in order to address various social problems and improve functioning of individual, group and community in general. Scope of basic tasks for social workers in work with families with children is quite broad and it includes tasks such as: manage client problem addressing process by involving also other professionals, for example, psychologists, social pedagogues, specialists from custody court, family doctors, etc., support and promote abilities of a client to adapt to social and physical environment, plan for client the most appropriate social services and social assistance.

In social service offices social work of families with children needs to be developed. Rights of a child to adequate living standard are basic rights worldwide. Well-being of a child is crucial for every society as children is our future. Notion of child well-being in every society is related to stability and security. Main problems regarding children rights protection are related to unsatisfactory preventive work - a child receives care dilatory. There is still a lack of social workers in Latvia who work with families with children. In small municipalities, social worker functions are often performed by employees without 


\section{SHS Web of Conferences}

proper education and those who take several positions. During economic crisis and with the increase of social tension also problems with children in risk families intensify, at the same time for making savings in schools there are being removed staff positions of social pedagogues and psychologists (in rural and urban territories).

To organize social work professionally, social workers have to obtain second level professional higher or academic education in social work field, but social carers, social assistance organizers and social rehabilitators - with first level professional higher education in relevant field. Analyzing statistical data it is clear there is still a lack of social work specialists in municipalities in 2009. In order to ensure the norm defined in legal acts, on average there should be 2255 social work specialists in municipalities in total. In 2009 compared to 2008, the amount of social work specialists with adequate education has increased by 7.5 percentages. In 2009 a professional social work in Latvia at social service offices performed 1206 social workers or 66 percentages from total number of required social work specialists. And this is still insufficient and hinders provision of professional social services for population. Violation of rights of a child is and will be discovered too late. In this situation important support for child protection could ensure non-governmental organizations and public participation in identifying violation of child rights, preventive measures, and family rehabilitation. Addressing of issues related to rights of a child, social security, education, employment a.o. provide several different level institutions which are not mutually interrelated. Activity of institution is focused on a child in crisis situation, vulnerable, needy family and not healthy family in general, thereby working with consequences and prevention hereof. In the state there is no common and single coordination mechanism to coordinate policies and implemented measures for protection of family interests and provision of necessary support. It results in overlapping of functions foreseen for institutions' activity tasks or these are not addressed at all, considering that this is a task of another institution.

Specialists who work in social service office shall assess client's needs, material and individual resources, as well as shall involve families themselves in addressing their problems. Only following such exhaustive assessment of needs the best solution may be found to prevent or reduce social problems of people and families or even separate groups. Successful solution of situation defines several substantial factors two of which comprise available resources - social services and municipal social benefits, and professional competence and education of social work specialists. Currently, it is urgent to work with families with children by developing social work in social service offices.

For families who have no experience in developing a functional family may really appear that their circumstances and the way of living comply with standards accepted in society in which they live. One of the tasks for social worker is to facilitate the improvement of functioning abilities of this family and self-assistance abilities by involving team of professionals. Implementation of this task requires broad resources for social worker - already mentioned work by team of professionals, specialists who may help family, also material assistance possibilities for family a.o. support. However, I would like to draw attention that social worker is not a professional who does everything that family cannot, does not want or is not able to do. Social worker does not take responsibility instead of someone else and is not responsible for situations where seems that there is no solution. Professional does not take decisions instead of the family and does not determine which would be the best solution in specific social case. Whereas social worker is a professional who facilitates the development of self-assistance abilities of a family in active cooperation with family, or person by applying a broad range of professional social work methods. Often a very long time is required for family to see, understand, accept its problem and realize its influence on family's functioning, and finally to address the problem. If person lacks motivation to cooperate, it is a major obstacle for solution of the problem. State's support is very small for development and growth of this profession that proves the lack of understanding about social work significance and content also in Latvian state government system.

It is known that in many Latvian municipalities assistance of social worker and necessary assistance resources are still not available. There are situations when inevitable has taken place, and then it is very 


\section{Int. Conf. SOCIETY. HEALTH. WELFARE; Congr. of Rehabilitation Doctors of Latvia}

important to identify the real causes of the problem or even tragedy and focus on people who have the most substantial and primary role in addressing situation in the family - parents. Primarily parents are responsible for their children but if parents cannot deal with their duties then state should take charge of children by providing them short-term or long-term out of familial care and upbringing. Social worker is one of the specialists whose aim is to provide professional support and assistance to family so that children could grow in their family and be together with their parents. However, it is not possible if family does not want to cooperate.

Two most important reasons for insufficient social work support for families with social problems, as I mentioned before, are as follows: insufficient amount of social work specialists per specific number of population thereby it is not possible to effectively provide assistance; and wages for social workers are very low. It results in situation where many successful professionals go to work in another field that is better paid.

Anyway, social worker is a person to whom people may apply in any situation irrespective if this person has declared it's place of residence in particular local government or not. Currently Law defines that assistance and services may assign only according to declared place of residence of the claimant. Yet simple consultation especially if a person has become in crisis situation is available for everyone that could be a start for solution of complex situation.

\section{Conclusions}

Social exclusion is a very diverse and serious public problem. Therefore reduction of it should be regarded as one of the main relevant issues for each country which considers facilitation and provision of welfare for its inhabitants as its main task. Solution of poverty and social exclusion as multidimensional and complex problem depends on effective cooperation among many institutions and organizations. Along with cooperation at the state level among ministries and other institutions also cooperation at regional and local level is of major importance. Also cooperation with non-governmental organizations, social partners, researchers and socially excluded people themselves is important in developing polices, implementing measures, monitoring and analysis. Municipal social workers directly have a relevant role in reducing social exclusion. These are people who facilitate co-participation of a client in improving own living quality in the longer-term by offering social services and assistance most appropriate to client's needs and resources.

Non-governmental organizations and social partners are widely involved in social inclusion policy development and decision-taking. Active cooperation with non-governmental organizations continues by implementing common projects, developing legal acts and participating in working groups, thereby promoting awareness of both parties as well as participation of non-governmental sector in decisiontaking processes.

What could be the main challenges for the future?

The one could be sufficient funding for preventive measures including family consultation, education and rehabilitation; make field policy assessing and considering it's impact on families. Define targeted measures for the most vulnerable population groups including families to reduce negative impact caused by inflation on population groups with small and medium income. Offer complex solutions for prevention of causes as currently major work is invested in reduction of consequences. Also activity of institutions is targeted to child in crisis situation, vulnerable, needy family and not healthy family in general, i.e., work is carried out with specific population groups, consequences and elimination hereof.

Under current situation in Latvia the work load for social service offices increases as well as for social workers and other social work specialists but social work quality should not suffer from that. I would like to believe that families in Latvia would not be left without support by social worker and situation in country will change to the right direction. Currently, social service office is the only place where a person free of charge may go in crisis situation and speak about issues urgent for him/her. 


\section{SHS Web of Conferences}

\section{References}

Bronfenbrenner, U. (1979) The ecology of human development: experiments by nature and design. Cambridge: Harvard University Press.

Gosh, Z. (2005) Child poverty and it's social consequences in Latvia. Life issues X. Riga: HSSWSP Attīstība

Reinholde, I., Vanaga, D. (2002) Social work with high risk families. Training methodological material. - Riga: HSSWSP Attīstība.

Cummings, E.M., Davies, P.T., Campell, S.B. (2000) Developmental psychopathology and family process. Theory, research and clinical implications. New York: The Guitford Press.

Pranka, M., Millere, J. (2009) Analysis on situation in Latvia in child rights protection field regarding children of out of familial care and children under risk to loose their familial care. Riga, contracting authority: association "Latvijas SOS Bērnu ciematu asociācija".

Room, G.J. (1999) Social Exclusion, Solidarity and the challenge of Globalisation. International Journal of Social Welfare: Volume 3. Blackwell Publisher, Oxford, UK and Boston, USA. - Number 3, July.

Wilkinson, R.G. (1996) Unhealthy societies. The afflictions of inequality. London, New York: Routledge. 